Corrigendum

\title{
Corrigendum to "Electropolished Titanium Implants with a Mirror-Like Surface Support Osseointegration and Bone Remodelling"
}

\author{
Cecilia Larsson Wexell, ${ }^{1,2,3}$ Furqan A. Shah, ${ }^{2,3}$ Lars Ericson, ${ }^{4}$ Aleksandar Matic, ${ }^{5}$ \\ Anders Palmquist, ${ }^{2,3}$ and Peter Thomsen ${ }^{2,3}$ \\ ${ }^{1}$ Department of Oral and Maxillofacial Surgery, Public Dental Service, Region Västra Götaland, SÄS, Borås, Sweden \\ ${ }^{2}$ Department of Biomaterials, Institute of Clinical Sciences, Sahlgrenska Academy at University of Gothenburg, Göteborg, Sweden \\ ${ }^{3}$ BIOMATCELL VINN Excellence Center of Biomaterials and Cell Therapy, Göteborg, Sweden \\ ${ }^{4}$ Department of Medical Biochemistry and Cell Biology, Sahlgrenska Academy at University of Gothenburg, Göteborg, Sweden \\ ${ }^{5}$ Department of Physics, Chalmers University of Technology, Göteborg, Sweden
}

Correspondence should be addressed to Cecilia Larsson Wexell; cecilia.larsson@vgregion.se

Received 14 June 2017; Accepted 18 June 2017; Published 13 July 2017

\begin{abstract}
Copyright (C) 2017 Cecilia Larsson Wexell et al. This is an open access article distributed under the Creative Commons Attribution License, which permits unrestricted use, distribution, and reproduction in any medium, provided the original work is properly cited.
\end{abstract}

In the article titled "Electropolished Titanium Implants with a Mirror-Like Surface Support Osseointegration and Bone Remodelling" [1], Figures 5(a), 5(b), and 5(c) are replaced since they were inadvertently reused from L. Sennerby,
P. Thomsen, and L. E. J. Ericson, "Early tissue response to titanium implants inserted in rabbit cortical bone," Journal of Materials Science: Materials in Medicine, vol. 4, no. 5, pp. 494-502, 1993. The correct Figure 5 is as follows.

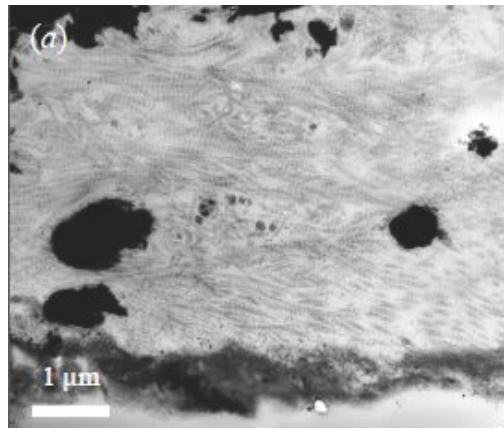

(a)

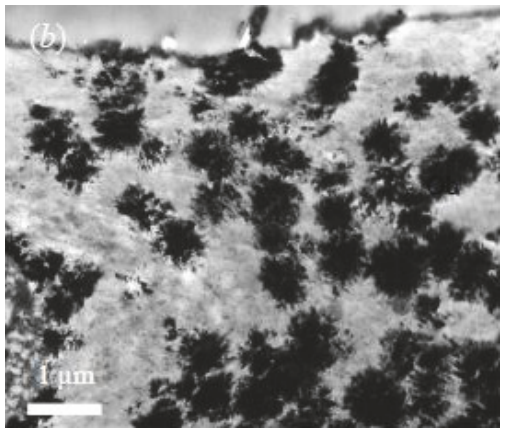

(b)

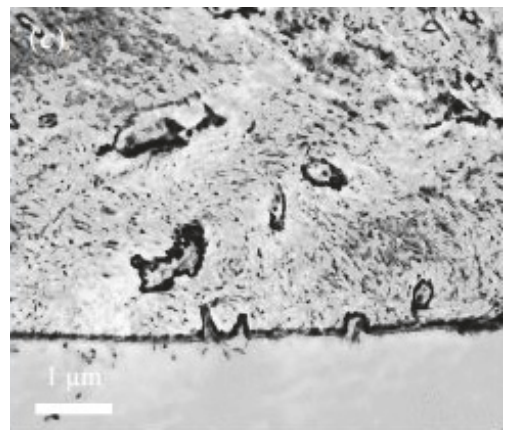

(c)

Figure 5: Continued. 


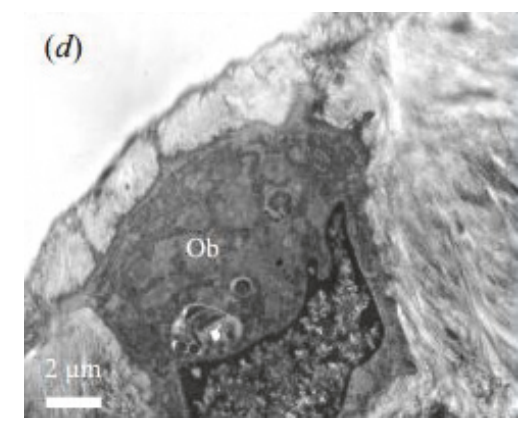

(d)

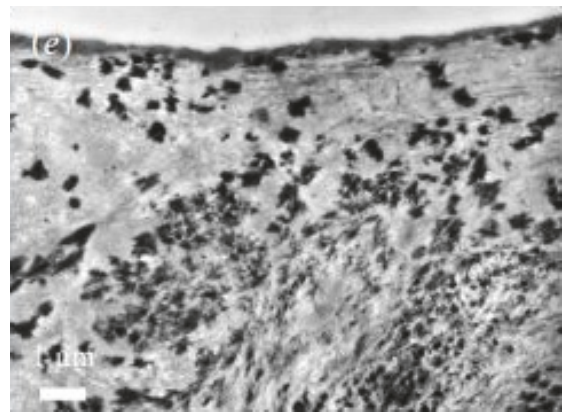

(e)

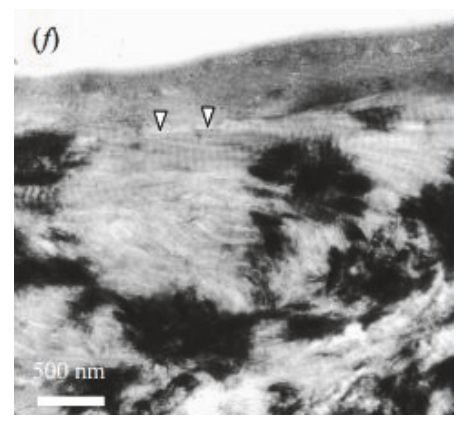

(f)

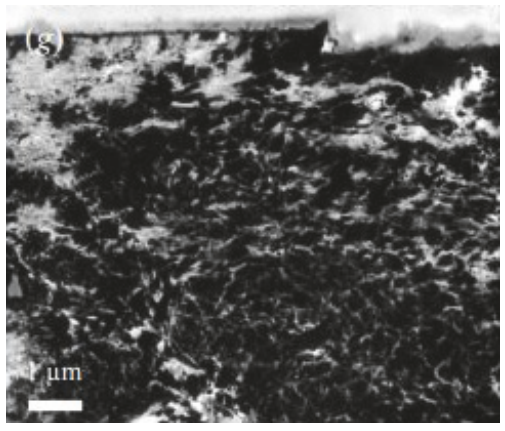

(g)

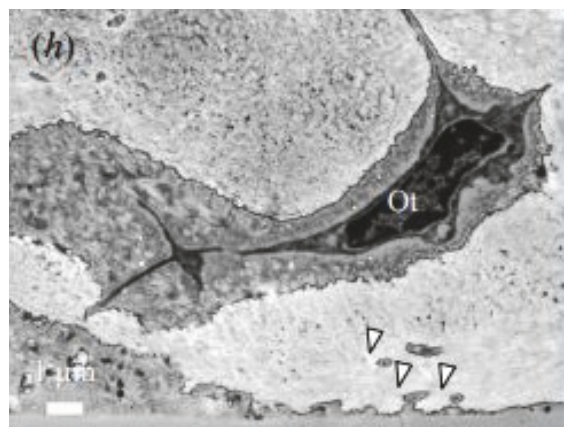

(h)

FIgURE 5: Transmission electron microscopy. The various stages of bone formation adjacent to the Ep surface could be observed at 12 weeks of healing. $(\mathrm{a}-\mathrm{c})$ At the bone-implant interface, osteoblasts $(\mathrm{Ob})$ produce an unmineralised extracellular matrix, the osteoid, which undergoes progressive mineralisation. (d) Collagen fibrils are aligned parallel to the osteoblast surface. (e) Early mineralisation stage with patchy distribution of bone apatite (dark areas). (f) In high-resolution, the characteristic $67 \mathrm{~nm}$ cross-striated pattern of collagen fibrils (white arrows) can be observed, with accumulation of intra- and interfibrillar mineral. (g) Late mineralisation stage with diffuse distribution of bone apatite (dark areas). (h) An osteocyte (Ot) embedded within the mineralised matrix lies in close proximity to the implant surface with several dendritic processes residing within canaliculi (white arrows), sectioned longitudinally as well as transversally, extending towards the implant surface.

\section{References}

[1] C. L. Wexell, F. A. Shah, L. Ericson, A. Matic, A. Palmquist, and P. Thomsen, "Electropolished titanium implants with a mirrorlike surface support osseointegration and bone remodelling," Advances in Materials Science and Engineering, vol. 2016, Article ID 1750105, 10 pages, 2016. 

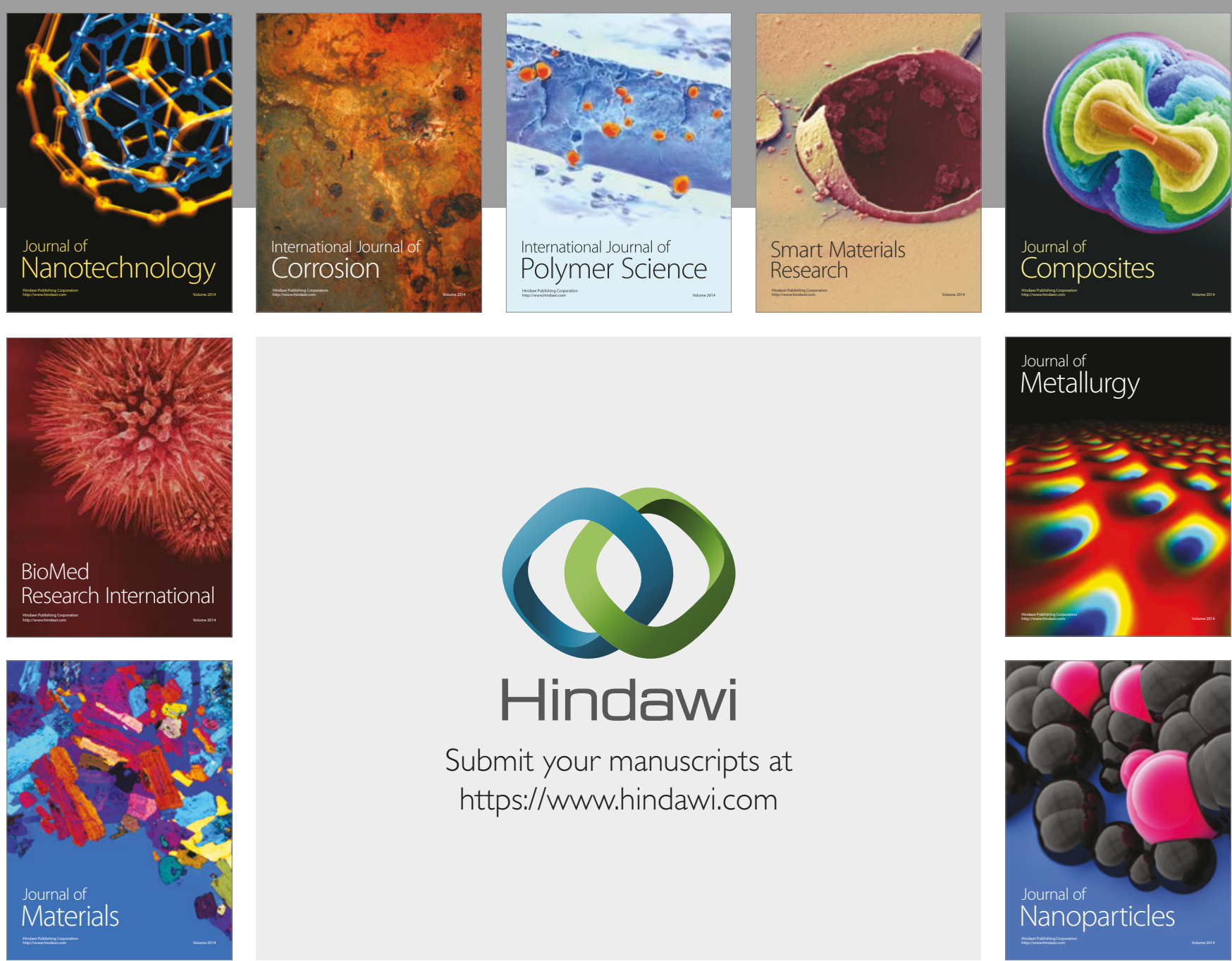

\section{Hindawi}

Submit your manuscripts at

https://www.hindawi.com
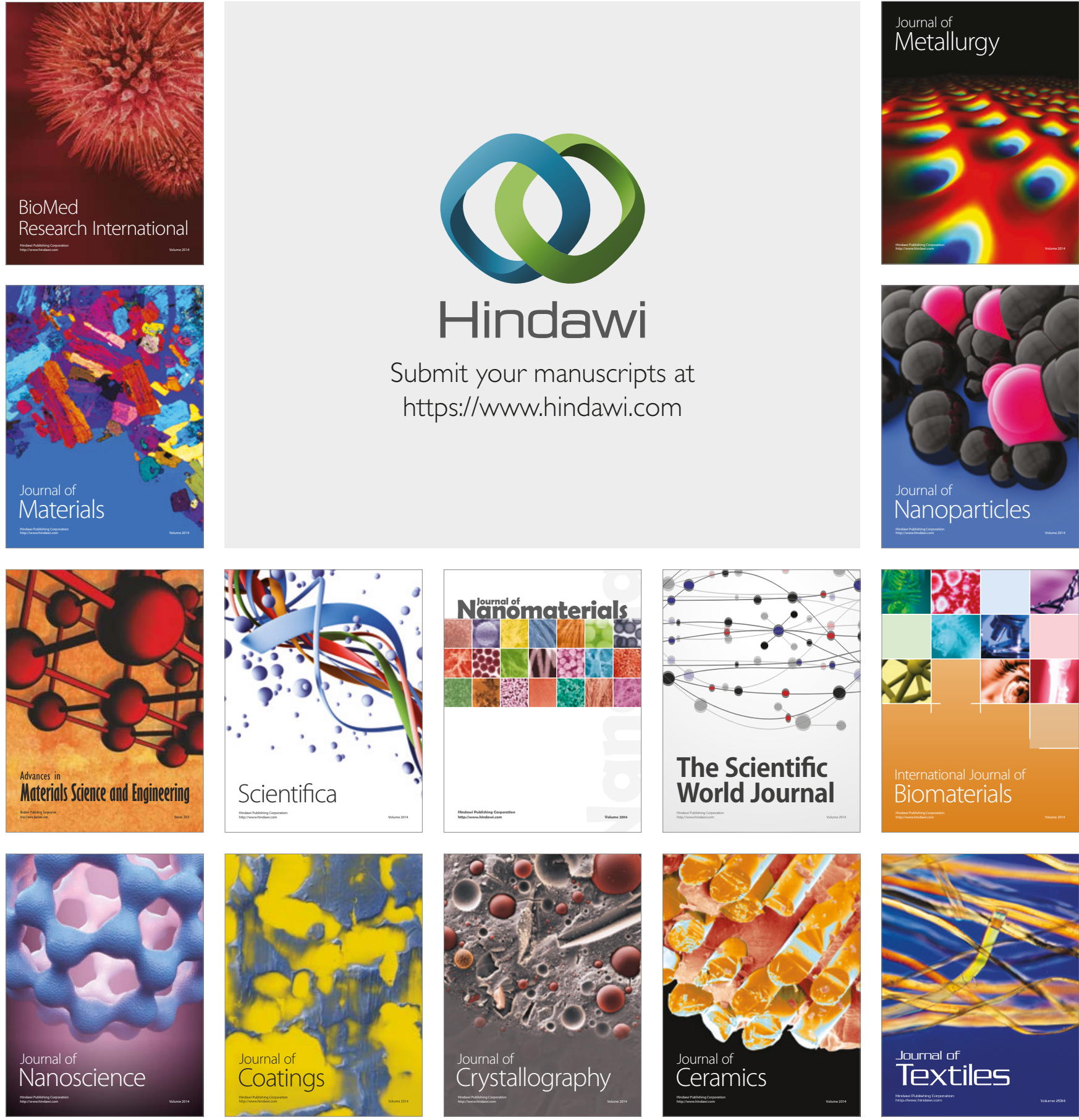

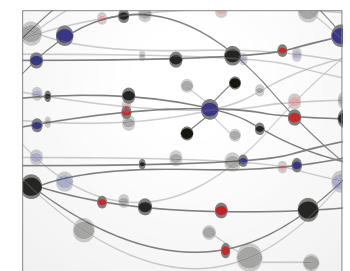

The Scientific World Journal
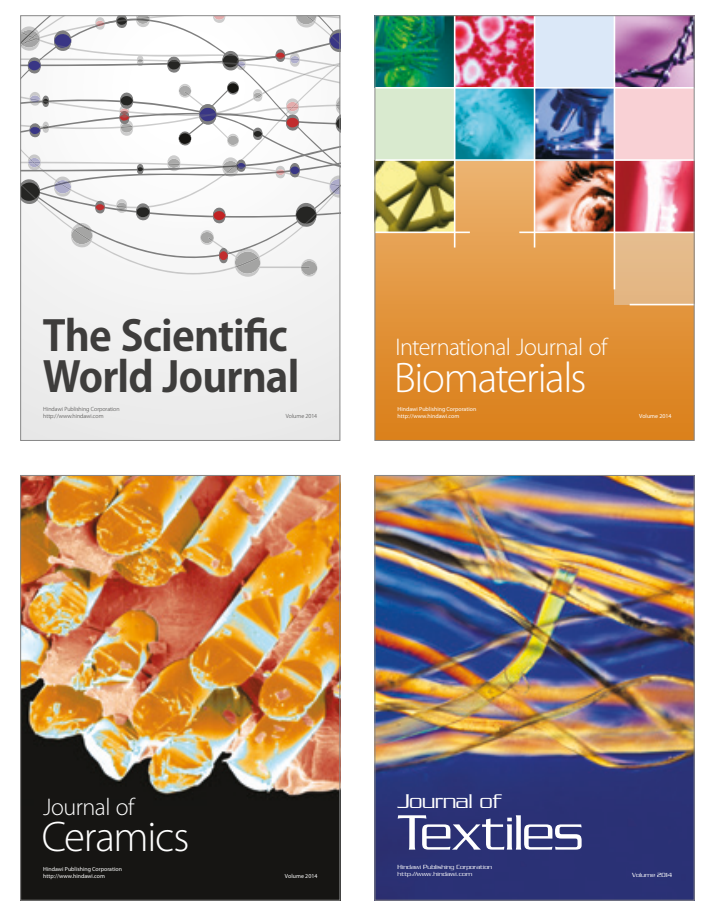